\title{
Thromboelastometry (Tem) in Pregnant Women: Basal Tem Profile and Tem Profile after Carbetocin Administration in Women at High Risk for Post-Partum Haemorrhage
}

\author{
Carlotta Montagnoli ${ }^{1}$, Giovanni Larciprete ${ }^{1^{\star}}$, Maria Grazia Frigo ${ }^{2}$, Benedetta Zuppani ${ }^{2}$, Herbert Valensise ${ }^{3}$, Maria \\ Elisabetta Romanini ${ }^{1}$, Valentina Panetta ${ }^{4}$, Mario Filippo Segatore ${ }^{1}$
}

${ }^{1}$ Department of Obstetrics and Gynaecology and A.Fa.R., Fatebenefratelli Isola Tiberina Hospital, Rome. Italy

${ }^{2}$ Department of Anesthesiology and Intensive Care, Fatebenefratelli Isola Tiberina Hospital, Rome. Italy

${ }^{3}$ Department of Obstetrics and Gynaecology, Tor Vergata University, Rome, Italy

${ }^{4}$ Laltrastatistica srl, Rome, Italy

\section{Abstract}

The aims of this study were to evaluate the thromboelastometry profile in pregnant at risk of post-partum haemorrhage and evaluate changes in thromboelastometry profile after administration of Carbetocin, used as uterotonic drugs in this patients during caesarean section. Twenty-one women undergoing elective caesarean section were consecutively enrolled, with risk factors for primary post-partum haemorrhage. All patients underwent the same combined spinal-epidural (CSE) anaesthesia. A basal thromboelastometry profile was performed. Women according to the study protocol received 500 $\mathrm{ml}$ of $0.9 \% \mathrm{NaCl}$ solution IV and as uterotonic drug a bolus of $100 \mu \mathrm{g}$ IV of Carbetocin at delivery of the anterior shoulder. Five minutes after uterotonic infusion, a new blood sample was performed for thromboelastometry profile after Carbetocin. Considering the changes in thomboelastometry profile before and after Carbeton, TEM exhibited significantly lower in MCF (in-TEM and ex-TEM) $(p<0.01)$ and in A10 (in-TEM and ex-TEM) $(p<0.01)$. We note also a significantly higher CFT ex-TEM value after Carbetocin $(p<0.01)$.
\end{abstract}

\section{Introduction}

Post-partum haemorrhage (PPH) is a major cause of maternal mortality and morbidity worldwide. The study conducted by the International PPH Collaborative Group, reports an increasing trend in coded PPH between 1991 and 2006 not only in low income countries, but also in Canada, New South Wales and the USA, as a possible result of increased maternal age at childbirth, increased rate of caesarean delivery, increased rate of induction of labor and higher number of multiple pregnancies [1]. The primary $\mathrm{PPH}$ is defined as blood loss more than $500 \mathrm{~mL}$ after vaginal delivery and more than $1000 \mathrm{~mL}$ after caesarean section, which occurs in the first 24 hours after delivery [2]. Non fatal consequences of PPH can to be further interventions, severe anaemia, need of blood transfusion, Sheehan's syndrome (pituitary infarction), coagulopathy and organ damage due to hypotension and shock. However, even today almost 500.000 women die for this potentially preventable cause each year [3]. The gravity of the bleeding and the presence of haemorrhagic shock depend on the amount of blood lost (Table 1) [4].

\begin{tabular}{|l|l|l|l|l|}
\hline & \multicolumn{4}{|c|}{ Class } \\
\hline Parameter & I & II & III & IV \\
\hline Blood Loss(ml) & $<750$ & $750-1500$ & $1500-2000$ & $>2000$ \\
\hline Blood Loss (\%) & $<15 \%$ & $15-30 \%$ & $30-40 \%$ & $>40 \%$ \\
\hline Pulse Rate & $<100$ & $>100$ & $>120$ & $>140$ \\
\hline Blood Pressure & Normal & Decreased & Decreased & Decreased \\
\hline Respiratory Rate & $14-20$ & $20-30$ & $30-40$ & $>35$ \\
\hline Urine Output & $>30$ & $20-30$ & $5-15$ & Negligible \\
\hline CNS Symptoms & Normal & Anxious & Confused & Lethargic \\
\hline
\end{tabular}

Table 1: Classification of haemorrhage.

Pulse rate in beats/min; Respiratory rate in breaths/min; Urine output in $\mathrm{ml} /$ hour.
The causes oh haemorrhage are defined on the basis of International Classification of Disease (ICD) codes recorded in Perinatal Database (ICD-9 and ICD-10) as shown in table 2 [5].

\begin{tabular}{|l|l|l|l|}
\hline Cause of PPH & $\begin{array}{l}\text { ICD-9 } \\
\text { coding }\end{array}$ & $\begin{array}{l}\text { ICD-10 } \\
\text { coding }\end{array}$ & $\begin{array}{l}\text { Scottish Data } \\
\text { Classification }\end{array}$ \\
\hline $\begin{array}{l}\text { Third stage hemorrhage } \\
\text { (Postpartum hemorrhage due } \\
\text { to retained placenta) }\end{array}$ & 666.0 & 072.0 & $\begin{array}{l}\text { Hemorrhage due to } \\
\text { retained products }\end{array}$ \\
\hline $\begin{array}{l}\text { Other immediate poatpartum } \\
\text { hemorrhage, within t he first } \\
\text { 24 hours following delivery of } \\
\text { placenta(Uterine atony) }\end{array}$ & 666.1 & 072.1 & $\begin{array}{l}\text { Hemorrhage due to } \\
\text { uterine atony }\end{array}$ \\
\hline $\begin{array}{l}\text { Delayed and secondary } \\
\text { postpartum hemorrhage } \\
\text { (after the first 24 hours } \\
\text { following delivery) }\end{array}$ & 666.2 & 072.2 & (n) \\
\hline $\begin{array}{l}\text { postpartum coagulation } \\
\text { defects }\end{array}$ & 666.3 & 072.3 & $\begin{array}{l}\text { Hemorrhage due to } \\
\text { placental abruption, } \\
\text { placenta previa, trauma } \\
\text { or other causes }\end{array}$ \\
\hline Other causes & & & \\
\hline
\end{tabular}

Table 2: Classifications and coding for causes of $\mathrm{PPH}$.

"Corresponding Author: Dr. Larciprete Giovanni, Department of Obstetrics and Gynaecology, Fatebenefratelli Isola Tiberina Hospital, Isola Tiberina 39, 00186, Rome, Italy, Tel: 0039-06-6837416; Fax: 0039-06-68214220; E-mail: giovanni.larciprete@fbf-isola.it

Citation: Montagnoli C, Larciprete G, Frigo MG, Zuppani B, Valensise H, et al. (2014) Thromboelastometry (Tem) in Pregnant Women: Basal Tem Profile and Tem Profile after Carbetocin Administration in Women at High Risk for Post-Partum Haemorrhage. Int J Gynecol Clin Pract 1: 103. doi: http://dx.doi. org/10.15344/2394-4986/2014/103

Copyright: ( 2014 Montagnoli et al. This is an open-access article distributed under the terms of the Creative Commons Attribution License, which permits unrestricted use, distribution, and reproduction in any medium, provided the original author and source are credited. 
Citation: Montagnoli C, Larciprete G, Frigo MG, Zuppani B, Valensise H, et al. (2014) Thromboelastometry (Tem) in Pregnant Women: Basal Tem Profile and Tem Profile after Carbetocin Administration in Women at High Risk for Post-Partum Haemorrhage. Int J Gynecol Clin Pract 1: 103. doi: http://dx.doi. org/10.15344/2394-4986/2014/103

Page 2 of 6

The first cause of haemorrhage at the time of delivery is uterine atony, therefore the Society of Obstetricians and Gynaecologists of Canada (SOGC) [6] suggest that the active management of the third stage of labour reduces the risk of PPH compared with the expectant management and should be offered and recommended to all women. A central role in the active management is the administration of uterotonic drugs. At the moment we haven't a ideal agent to use as prophylactic: although the Oxytocin is the most widely accepted uterotonic agent. However other drugs are available, Misoprostol, Syntometrine, and Carbetocin. Carbetocin is a long-acting synthetic oxytocin analogue, 1-deamino-1-monocarbo-(2-O-Methyltyrosine)oxytocin, firstly described in 1987. It has a half-life of 40 minutes (around 4-10 times longer than oxytocin) and uterine contractions occur in less than two minutes after intravenous administration of optimal dosage of $100 \mu \mathrm{g}$ [6]. A single dose of Carbetocin has been hypothysed to act as a 16 hours intravenous Oxytocin infusion regarding the increase in uterine tone and the reduction of the risk of $\mathrm{PPH}$ in elective caesarean section [7].

Several data of literature [8-10] suggest that prophylactic administration of Carbetocin may be a good alternative to Oxytocin to prevent post-partum haemorrhage and $\mathrm{Su}$ et al. in the Cochrane of 2007 regarding "Oxytocin agonists for preventing postpartum haemorrhage" and in the Cochrane 2012 regarding "Carbetocin for preventing postpartum haemorrhage", conclude that the use of Carbetocin is more effective than Oxytocin for preventing PPH in women undergoing caesarean section, but the data and the evidences were still insufficient [10-13].

Also, our research group in a recent study demonstrated that a single injection of Carbetocin has more effective than a continuous infusion of Oxytocin to maintain adequate uterine tone, with a similar safety profile and minor antidiuretic effect, and a very good haemodynamic profile [14].

In critically patients, as women with $\mathrm{PPH}$, is very difficult to estimate the exact blood loss and evaluate the presence of coagulation disorders. Indeed the routine coagulation assay includes the evaluation of prothrombine time (PT) or international normalize ratio (INR) and activated partial thromboplastin time (aPTT) to monitor respectively the extrinsic and intrinsic pathways, however these tests are performed usually only on plasma, therefore they don't considerer the role of platelets in the clotting formation. In this regard the use of Thromboelastography (TEG) was proposed in presence of $\mathrm{PPH}$, to evaluate the efficiency of clot formation and fibrinolysis $[15,16]$.

The thromboelastography is a method for testing the efficiency of blood coagulation, developing by Dr. Helmut Hartert in 1948, considering a coagulation as a dynamic process [17]. In the 199597 was developed an improvement of TEG, the ROTEM system (or Thromboetlastometry-TEM).

Variable of interest in ROTEM are: the clotting time (CT) that is the time until there is first evidence of clot; the clot formation time (CFT) that is the time from CT until the clot reaches $20 \mathrm{~mm}$ and this represents the speed of solid clot formation; the angle $(\alpha)$ is the tangent of the curve made as the CFT is reached and offers similar information to CFT; the Maximum Clot Firmness (MCF) is the greatest vertical amplitude of the trace and it is reflection of clot strenght (fibrin and platelet clot); the maximum lysis (ML) indicates the percentage of lost clot stability (relative to MCF, in \%); A10 describe the clot firmness obtained after 10 minutes and provide forecast on the expected MCF value at an earlier stage already and this allows for a more rapid decision about therapeutic intervention [18] (Figure 1).

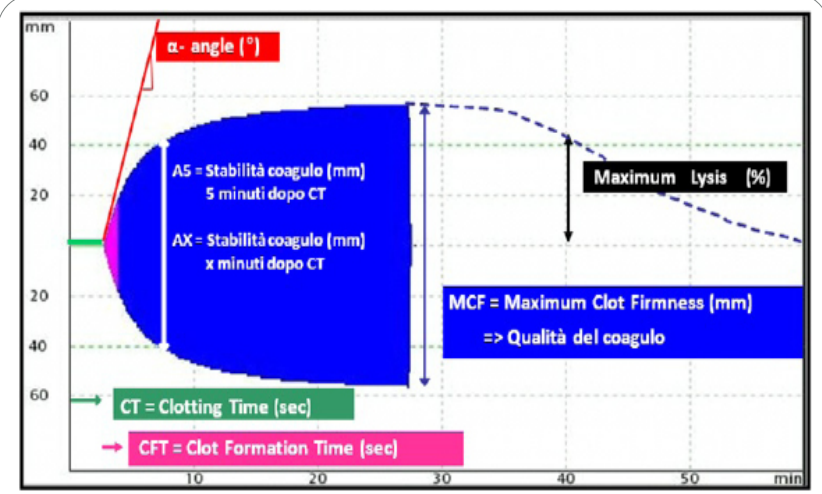

Figure 1: Normal TEM tracing (formation and degradation of clot).

Initially the TEG was performed simply with whole blood without adding reagents and this provided a global overview about all phases of clot formation, stabilization and degradation. But now thanks to the addition of reagents you can assesses separately the intrinsic (inTEM) and the extrinsic (ex-TEM) coagulation pathways.

Therefore whit the ROTEM system you may have rapidly available results enable a differential diagnosis, discriminating between surgical bleeding and a haemostatic disorder, hyperfibrinolysis, dilutional coagulopathy and requirement for fibrinogen or platelet substitution [19].

Our study comes from the knowledge that in PPH a new transfusion strategy based on transfusion of packed red blood cells, fresh frozen plasma and platelets improves dilutional coagulopathy and survival [15]. In this regard it is proposed that TEM may play an important role in post-partum haemorrhage by helping clinicians rapidly identify and treat exactly the deficiency in question [16]. The aims of this study were to evaluate the thromboelastometry profile in pregnant at risk of post-partum haemorrhage and evaluate changes in thromboelastometry profile after administration of Carbetocin, used as uterotonic drugs in this patients during caesarean section.

\section{Methods}

This study is conducted from January to February 2012 within the Obstetric and Gynaecology tertiary care unit of Fatebenefratelli Isola Tiberina, Rome.

Twenty-one women undergoing elective caesarean section were consecutively enrolled, with risk factors for primary post-partum haemorrhage such as: multiple pregnancy, two or more previous caesarean section, presence of uterine fibroids, previous myomectomy, presence of placenta previa, past history of $\mathrm{PPH}$, fetal macrosomia and fetal malformations associated with polyhydramnios.

A written informed consent was asked from eligible women on admission.

The exclusion criteria included the presence of hypertension, pre-eclampsia, cardiac, renal or liver diseases, epilepsy and general anaesthesia, as well as women with history of hypersensitivity to carbetocin according to the Br National Formulary [9].

Within these patients, 3 were carriers of thrombofilic factors (mutation of factor II, eterozigosis of MTHFR and Factor V Leiden). 
Citation: Montagnoli C, Larciprete G, Frigo MG, Zuppani B, Valensise H, et al. (2014) Thromboelastometry (Tem) in Pregnant Women: Basal Tem Profile and Tem Profile after Carbetocin Administration in Women at High Risk for Post-Partum Haemorrhage. Int J Gynecol Clin Pract 1: 103. doi: http://dx.doi. org/10.15344/2394-4986/2014/103

Page 3 of 6

All patients underwent the same combined spinal-epidural (CSE) anaesthesia.

Before the anaesthesia it was performed a blood sample $(5 \mathrm{cc})$ technique BD Vacutainer, according with the manifacturer's instructions. A basal thromboelastometry profile was performed. After the application of this anaesthesia, subjects were positioned in recumbent position and for continuous blood pressure measurement a limb cuff (Drager Infinity Delta ${ }^{\circ}$, Drager Medical Australia pty ltd) was applied. Women according to the study protocol received $500 \mathrm{ml}$ of $0.9 \% \mathrm{NaCl}$ solution IV and as uterotonic drug a bolus of $100 \mu \mathrm{g}$ IV of Carbetocin at delivery of the anterior shoulder. We recorded the occurrence of nausea, vomiting, flushing, haedache, dyspnea and tachycardia.

Five minutes after uterotonic infusion, a new blood sample was performed for thromboelastometry profile after Carbetocin.

\section{Thromboelastometry system (ROTEM)}

According with the manifacturer's instructions of ROTEM system ${ }^{\circ}$ (ROTEM ${ }^{\circ}$;Tem International GmbH,Munich,Germany), a whole is placed into a cuvette and cylindrical pin is immersed. Between pin and cuvette remains a gap of $1 \mathrm{~mm}$, bridged by the blood. The pin is rotated by a spring to the right and left. As long as the blood is liquid, the movement is unrestricted. When the blood starts clotting, the clots increasingly restrict the rotation of the pin with rising clot firmness. The kinetic is detected mechanically and calculated by an integrated computer. The traditional TEG system that works whit a free-pending pin in a rotating cuvette. Due to the free suspension of the pin, the TEG, is extremely sensitive to vibrations and mechanical shocks. Conversely, in the ROTEM this flaw is overcome by using a rotating pin, fixed on a steel axis which is stabilized by unique ball bearing and the precise optical detection method.

Thanks to the addition of reagents (ellagic acid and chloroform extract for the intrinsic pathway and recombinant tissue factor and phospholipids for the extrinsic pathway) it was performed the evaluation of the intrinsic pathway (in-TEM) and extrinsic pathway (Ex-TEM).

In-TEM: This test mildly activates the contact phase of haemostasis. The results is influenced by coagulation factors, platelets, fibrinogen and heparin. It is the screening for the intrinsic haemostasis system.

Ex-TEM: Test mildly activates haemostasis via the physiological activator tissue factor. The results are influenced by extrinsic coagulation factors, platelets and fibrinogen. Ex-TEM is a screening for the extrinsic haemostasis system.

For both pathways clotting characteristics are described by functional parameters: CT (clotting time), CFT (clot formation time), MCF (maximum clot firmness), A10 (clot firmness after 10 minutes) and ML (maximum lysis).

This study had no external funding source. No author had any potential relationships that may pose conflict of interest.

\section{Statistical analysis}

Data were expressed as means \pm SD or median, as appropriated. Data were tested for normal distribution. Statistical analysis was performed by using Mann Withney non parametric test or $\chi^{2}$ test and Fisher's
The STATA software version 12.0 was used for the statistical calculations.

\section{Results}

All women enrolled were subjected to elective caesarean section. Indications are: $11(52.6 \%)$ multiple pregnancy, $6(28.5 \%)$ two or more previous caesarean section, $2(9.5 \%)$ fetal macrosomia, $1(4.7 \%)$ previous myomectomy and $1(4.7 \%)$ presence of placenta previa. No patients had a past history of $\mathrm{PPH}$

Regarding the basal thromboelastometry in pregnancy, graphs in figure 2(a-h) show the distribution of TEM parameter, basal and after carbetocin, in pregnant compared to normal range considered by the manufacturer in non pregnant woman. All TEM parameters (CT, CFT, MCF, A10, ML) included in normal range suggested by the manufacturer. The MCF (in-TEM and ex-TEM) and A10 (inTEM and ex-TEM) are close to the maximum values of normality, in agreement with the observation that pregnant women are relatively hypercoagulable to minimize the risk of haemorrhage during delivery and post-partum period.

Considering the changes in thomboelastometry profile before and after Carbeton, TEM exhibited significantly lower in MCF (inTEM and ex-TEM) $(p<0.01)$ and in A10 (in-TEM and ex-TEM) $(p<0.01)$. We note also a significantly higher CFT ex-TEM value after Carbetocin $(p<0.01)$ (Figure 3$)$.

There wasn't any recorded adverse effects after Carbetocin administration.

\section{Discussion}

Is well known that coagulation cascade is highly regulated process relying on both enzymatic activity of clotting factors as well as proper platelet structure and function.

A normal pregnancy is associated with major changes in many aspects of haemostasis that create a state of hypercoagulability. These fisiological changes may be important for minimizing intrapartum and post-partum blood loss, but they entail risk of thromboembolism during pregnancy and in post-partum period [20]. The procoagulant activity in maternal blood is characterized by elevation of factors VII, $\mathrm{X}$, VIII, fibrinogen and von Willebrand factor, with is maximal around the term. This is associated with an increase in prothrombin fragments $(\mathrm{PF} 1+2)$ and throbin-antithrombin complexes. The decrease of physiological anticoagulant is marked by a significant reduction of Prot $\mathrm{S}$ activity and by acquired activated protein $\mathrm{C}$ resistance (aPCR) [21]. Also the fibrinolytic activity is impaired during pregnancy: tissue plasminogen activator activity decreased during pregnancy, due to the gradual increase in plasminogen activator-1 (PAI-1). but also to the increasing levels of plasminogen activator inhibitor-2 (PAI2) produced byvillous cells [22]. However the fibrinolytic activity return rapidly to normal following delivery. This is due specially to a placental derived plasminogen activator inhibitor type 2 (PAI-2) which is present in large quantities in pregnancy. After delivery, at level of placental throfoblast the local haemostasis is characterized by increased tissue factor and by low expression of inhibitor of tissue factor [23]. Therefore the reference ranges for the TEM must necessarily be different in pregnant population.

Consistently with the above, our data show that the ROTEM reference parameters that expresses the clot firmness (MCF and A10) are close to the maximum values of normality, whereas the CFT that 
Citation: Montagnoli C, Larciprete G, Frigo MG, Zuppani B, Valensise H, et al. (2014) Thromboelastometry (Tem) in Pregnant Women: Basal Tem Profile and Tem Profile after Carbetocin Administration in Women at High Risk for Post-Partum Haemorrhage. Int J Gynecol Clin Pract 1: 103. doi: http://dx.doi. org/10.15344/2394-4986/2014/103

Page 4 of 6
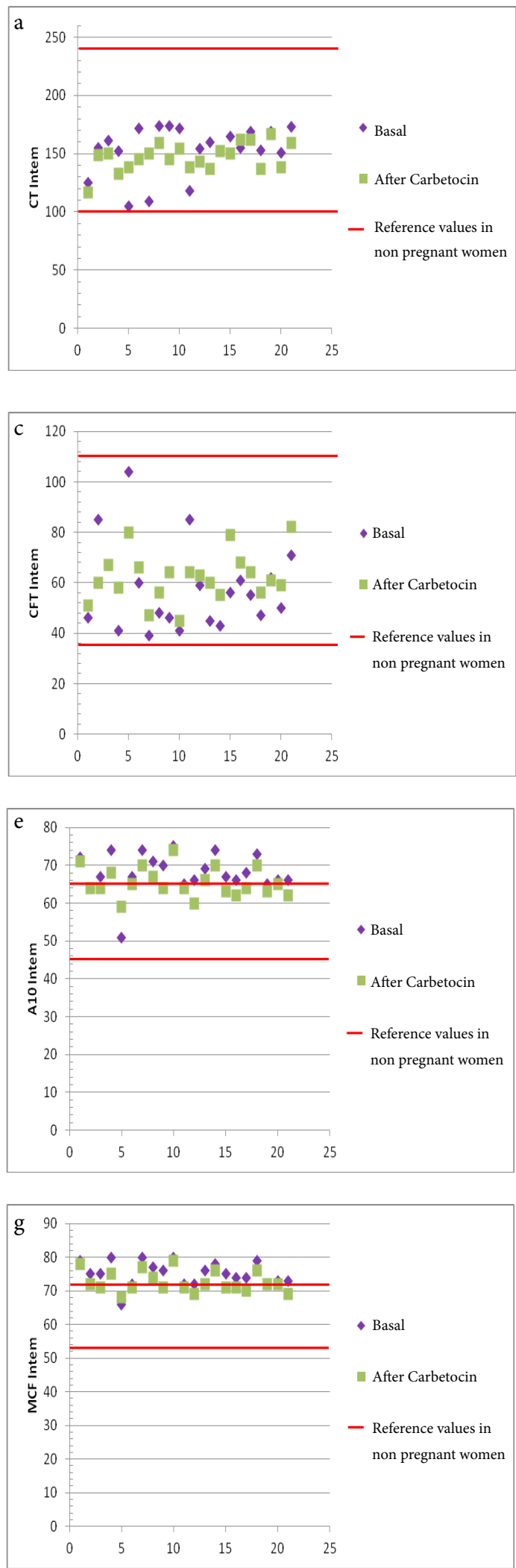

Figure 2: (a-h) Thromboelastometry profile in pregnant woman.
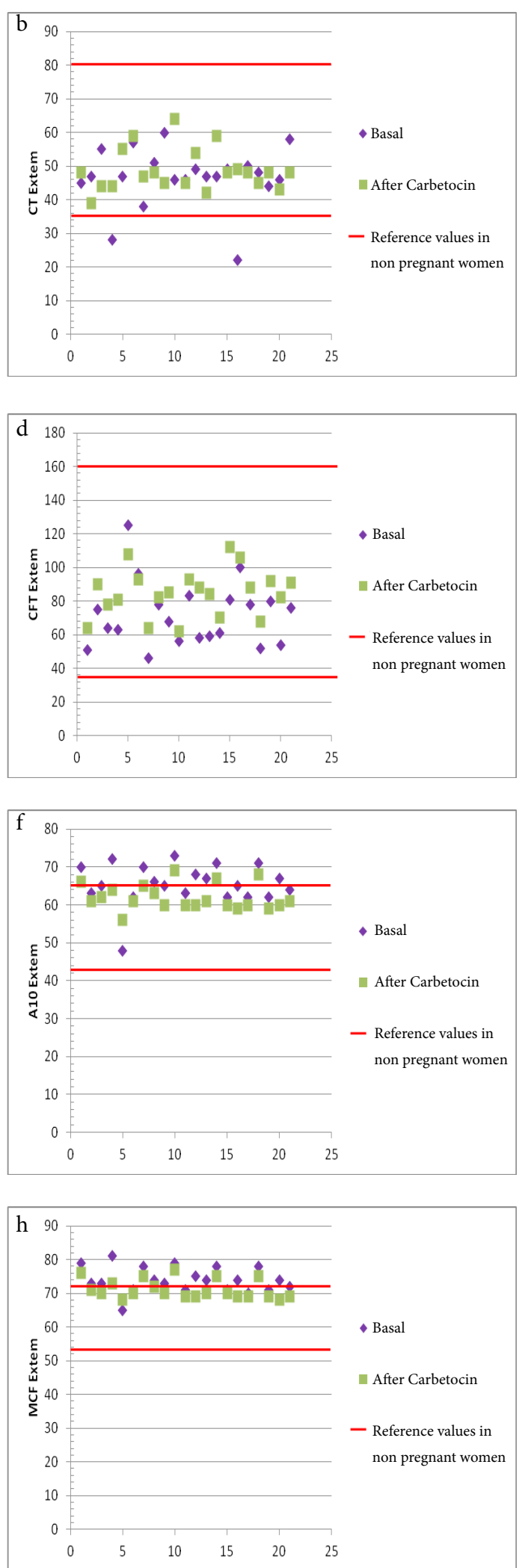
Citation: Montagnoli C, Larciprete G, Frigo MG, Zuppani B, Valensise H, et al. (2014) Thromboelastometry (Tem) in Pregnant Women: Basal Tem Profile and Tem Profile after Carbetocin Administration in Women at High Risk for Post-Partum Haemorrhage. Int J Gynecol Clin Pract 1: 103. doi: http://dx.doi. $\operatorname{org} / 10.15344 / 2394-4986 / 2014 / 103$

Page 5 of 6
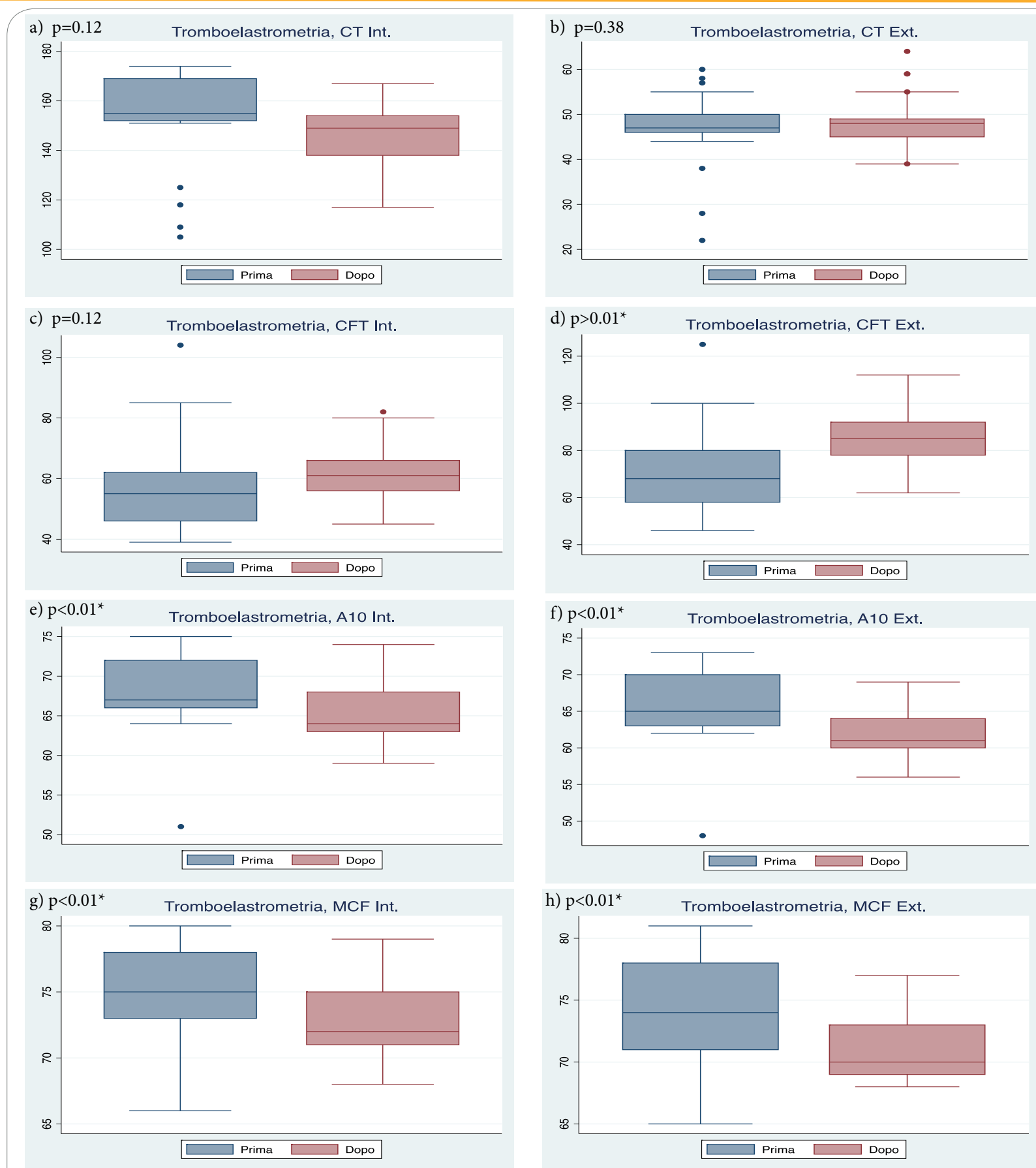

h) $\mathrm{p}<0.01^{*} \quad$ Tromboelastrometria, MCF Ext.
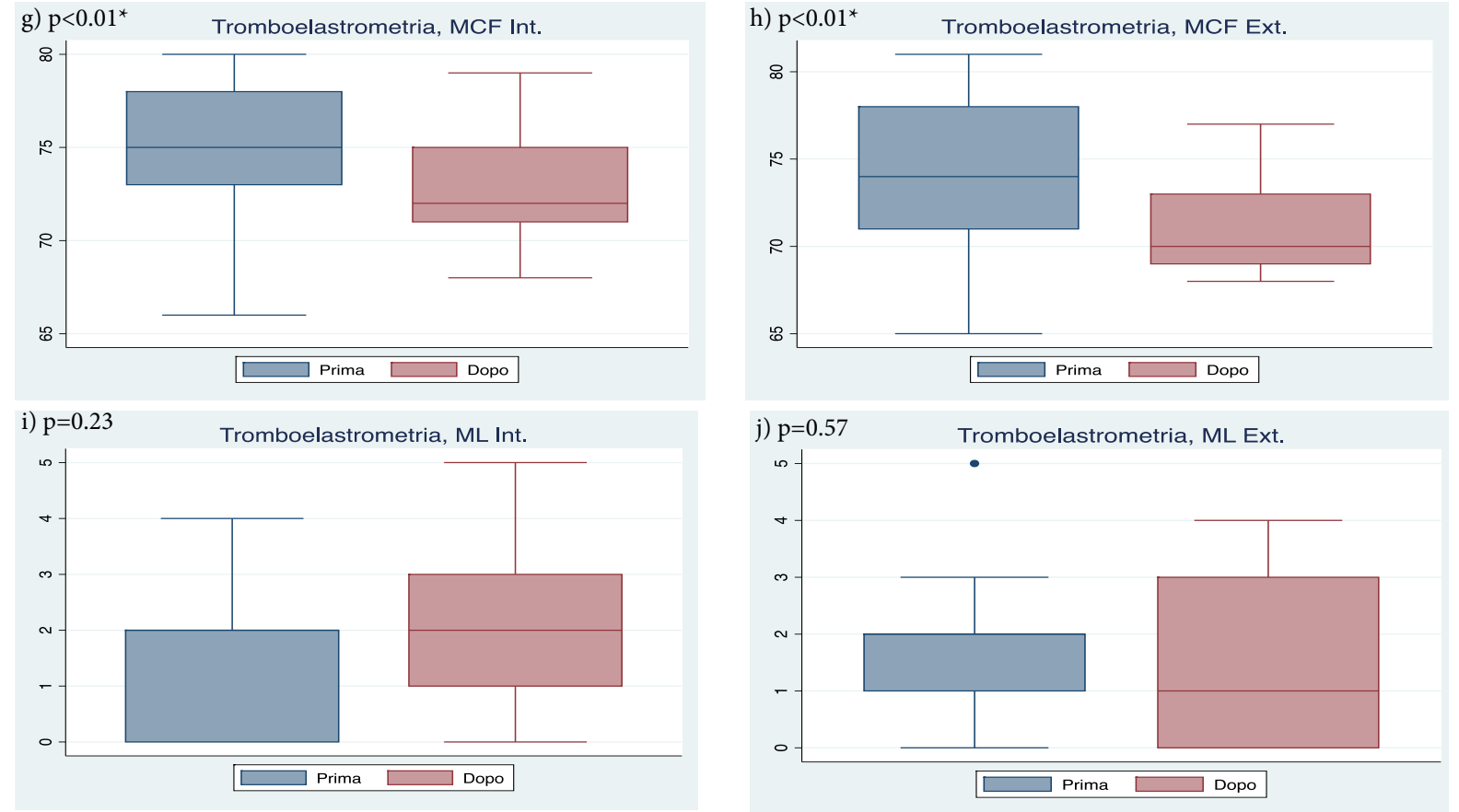

Figure 3: (a-l)Thromboelastometry profile before and after Carbetocin infusion. 
Citation: Montagnoli C, Larciprete G, Frigo MG, Zuppani B, Valensise H, et al. (2014) Thromboelastometry (Tem) in Pregnant Women: Basal Tem Profile and Tem Profile after Carbetocin Administration in Women at High Risk for Post-Partum Haemorrhage. Int J Gynecol Clin Pract 1: 103. doi: http://dx.doi. org/10.15344/2394-4986/2014/103

Page 6 of 6

denote the speed at which a solid clot forms, it tends to lower limits of reference ranges. In literature there have several published studies concerning reference ranges for TEG-thromboelastigraphy including some performed in pregnancy [23], but there are limited data avaible regarding ROTEM thromboelastometry in pregnant women. However our results are in agreement with Armstrong et al. that reported that thromboelastometry in pregnant women exhibited significantly lower CFT, and MCF significantly higher that in non-pregnant group [24].

Regarding modification thromboelastometry profile after Carbetocin infusion, our study shows a decrease of parameters that denote the clot firmness (MCF and A10) and against an increase of clot formation time (CTF). Therefore the values of TEM tend to return at reference ranges established for non pregnant population. This observation could be due to two observation. First, Carbetocin is administered after delivery of the anterior shoulder and our TEM profile was performed 5 minutes after Carbetocin administration. In this time often the placental delivery begins and we know that plasma fibrinolytic activity, reduced during pregnancy, returns to normal early after placental delivery, due stopping the production of PAI-2 by villous cells [22]. Secondly, that Carbetocin, as a long-acting oxytocin analog, prevents the PPH by a uterotonic action without modify a coagulation pathway. Indeed the Carbetocin, similarly to Oxytocin, it causes an increase in the intracellular concentration of calcium that promotes uterine contractility, through the generation of inositol phosphatas [24]. This evidence, associated to haemodynamic safety profile [14], they are important results in the attempt to define a more comprehensive assessment and possibility of application. Indeed preeclampsia and eclampsia are contraindications to the administration of Carbetocin currently, but the evidence of lack of prothrombotic effect suggest a new threshold in the attempt to enlarge the therapy indications.

ROTEM thromboelastometry is a whole blood method of coagulation monitoring and that rapidly provides a real time image of haemostasis, reducing delays in initiating appropriate patient treatment. However the TEM clearly demonstrates the hypercoagulability in pregnancy, therefore in management of post-partum haemorrhage you must to consider different reference ranges.

\section{Conlusion}

Moreover is essential to know the effects of drugs administered as prophylaxis or therapy of $\mathrm{PPH}$. To this end the Carbetocin appears safe and from our data seems that the values of TEM tend to return at reference ranges established for non pregnant population.

However, there are limited data available regarding this interesting argument in obstetrics population and we hope will be a stimulus for other centres to work in this area.

\section{References}

1. Knight M, Callaghan WM, Berg C, Alexander S, Bouvier-Colle $\mathrm{MH}$, et al. (2009) Trends in postpartum hemorrhage in high resource countries: a review and recommendations from the International Postpartum Hemorrhage Collaborative Group. BMC Preg Childbirth 9: 55.

2. WHO recommendations for the prevention and treatment of postpartum haemorrhage.

3. World Health Organisation (2005) The World health report 2005: make every mother and child count.

4. Gutierrez G, Reines HD, Wulf-Gutierrez ME (2004) Clinical review: haemorrhagic shock. Crit Care 8: 373-381.
5. Leduc D, Senikas V, Lalonde AB (2009) Clinical Practice Obstetrics Committee; Society of Obstetricians and Gynaecologists of Canada. Active management of the third stage of labour: prevention and treatment of postpartum hemorrhage. J Obstet Gynaecol Can 31: 980-983.

6. Sweeney G, Holbrook AM, Levine M, Yip M, Alfredson K, et al. (1990) Pharmacokinetics of carbetocin, a long acting oxytocin analogue, in nonpregnant women. Curr Ther Res 47: 528-540.

7. Boucher $M$, Horbay GL, Griffin $P$, Deschamps $Y$, Desjardins $C$, et al. (1998) Double-blind randomised comparison of the effect of carbetocin and oxytocin on intraoperative blood loss and uterine tone of patients undergoing caesarean section. J Perinatol 18: 202-207.

8. Attilakos G, Psaroudakis D, Ash J, Buchanan R, Winter C, et al. (2010) Carbetocin versus oxytocin for the prevention of postpartum haemorrhage following caesarean section: the results of a double-blind randomised trial. BJOG 117: 929-936.

9. Borruto F, Treisser A, Comparetto C (2009) Utilization of carbetocin for prevention of postpartum haemorrhage after caesarean section: a randomized clinical trial. Arch Gynecol Obstet 280: 707-712.

10. Boucher M, Nimrod CA, Tawagi GF, Meeker TA, Rennicks White RE et al. (2004) Comparison of carbetocin and oxyocin for the prevention of postpartum haemorrhage following vaginal delivery: a double-blind randomized trial. J Obstet Gynaecol Can 26: 481-488.

11. Su LL, Chong YS, Samuel M (2007) Oxytocin agonists for preventing postpartum haemorrhage. Cochrane Database Syst Rev 3: CD005457.

12. Su LL, Ching YS, Samuel M (2012) Carbetocin for preventing postpartum haemorrhage. Cochrane Database Syst Rev 15: CD005457.

13. Larciprete G, Montagnoli C, Frigo M, Panetta V, Todde C, et al. (2013) Carbetocin versus oxytocin in caesarean section with high risk of postpartum haemorrhage. J prenatal Med 7: 12-18.

14. Onwuemene O, Green D, Keith L (2012) Post-partum haemorrhage management in 2012: predicting and future. Int J Gyn Obstetrics 119: 3-5.

15. Trapani LM (2013) Thromboelastography:current applications, futuredirections. Open J of Anesthesiology 3: 23-27.

16. Kroll HM (2010) Thromboelastography: theory and practice in measuring hemostasis. Clinical Laboratory news 36: 8-10.

17. Olivier W, Wojciechowski Z, Sheinbaum R, Zisman E (1996) Thromboelastography. The Int J Anesthes 1:3.

18. Langenecker SK (2007) Management of massive operative blood loss Minerva Anesthesiol 73: 401-415.

19. Bremme KA (2003) Haemostatic changes in pregnancy. Best Pract Res Clin Haematol 16: 153-168.

20. Brenner B (2004) Haemostatic changes in pregnancy. Thromb Res 114: 409-414.

21. Prisco D, Ciuti D, Falciani M (2005) Haemostatic changes in normal pregnancy. Haematologica reports 1: 1-5.

22. Davies JR, fernando R, Hallworth SP (2007) Haemostatic function in healthy pregnant and preeclamptic women: an assessment using the platelet function analyzer (PFA-100) and thromboelastograph. Anest Analg 104: 416-420.

23. Armstrong S, Fernando R, Ashpole K, Simons R, Columb M (2011) Assessment of coagulation in the obstetric population using ROTEM thromboelastometry. Int J obstet Anesth 20: 293-298.

24. Engstrom T, Barth T, Melin P, Vilhardt H (1998) Oxytocin receptor binding and uterotonic activity of carbetocin and its metabolites following enzymatic degradation. Eur J Pharmacol 355: 203-210. 